\title{
Evolução geológica das sequências do embasamento do Cinturão Araguaia na região de Paraíso do Tocantins (TO), Brasil
}

\author{
Geologic evolution of basement sequences of Araguaia Belt at Paraíso \\ do Tocantins, Brazil
}

\author{
Silvia Helena de Souza Arcanjo ${ }^{1 *}$, Francisco de Assis Matos de Abreu², \\ Candido Augusto Veloso Moura ${ }^{2}$
}

\begin{abstract}
RESUMO: Estudos isotópicos baseados nas metodologias $\mathrm{Pb}-\mathrm{Pb}$ em zircão e $\mathrm{Sm} / \mathrm{Nd}$ (rocha total), permitiram avanços no entendimento do quadro geológico evolutivo e litoestratigráfico do embasamento do segmento sul do Cinturão Araguaia. Os processos geológicos identificados aconteceram a partir do Arqueano $\left(2,6 \mathrm{Ga} \mathrm{e}_{\mathrm{DM}} 2,78-\right.$ $3,25 \mathrm{Ga})$ e se estenderam até o Neoproterozoico. Os ortognaisses do Complexo Rio_dos Mangues posicionam-se no Paleoproterozoico $(2,05-2,08 \mathrm{Ga})$ e $\mathrm{T}_{\mathrm{DM}} 2,35-2,21 \mathrm{Ga}$. Um forte encurtamento crustal e fusão parcial de compartimentos isolados e espessados, gerou corpos ígneos de 1,85 e 1,82 Ga e o Granito Serrote (1,86 $\mathrm{Ga})$, que provêm de fontes entre 2,50 e 2,43 Ga. No final do Mesoproterozoico a regiáo foi marcada por processos tafrogenéticos, evidenciados por magmatismo máfico e alcalino $(1,05 \mathrm{Ga})$ e bacias deposicionais, como a que acolheu os sedimentos que originaram as supracrustais do Cinturão Araguaia. No Neoproterozoico, através da inversão nas condições geodinâmicas, ocorreu novo processo de encurtamento/espessamento crustal com fusóes que originaram expressivas massas batolíticas (Granitos Matança e Santa Luzia). O Cinturão Araguaia foi edificado a partir dessa movimentação tectônica. O transporte de massas tectônicas no sentido do Cráton Amazônico teria ocorrido, resultando na atual arquitetura em que se encontram as várias unidades lito-estratigráficas, organizadas sob a forma de lascas imbricadas.
\end{abstract}

PALAVRAS-CHAVE: Cinturão Araguaia; evolução geológica; geocronologia; $\mathrm{Pb}-\mathrm{Pb}$ em zircão; $\mathrm{Sm} / \mathrm{Nd}$

\begin{abstract}
Isotopic studies based on single zircon Pb-evaporation and $\mathrm{Sm} / \mathrm{Nd}$ (whole rock) methodologies, allowed advances at the lithostratigraphic scene and geologic evolution of basement, in the south segment of Araguaia Belt. The identified geological processes took place from the Achaean (2.6 Ga and $T_{D M}$ ages varying between 2.78 and $3.25 \mathrm{Ga}$ ) through Neoproterozoic Era. The Paleoproterozoic ortognaisses, represented by Rio dos Mangues Complex, are placed between 2.05 and $2.08 \mathrm{Ga}$, and they were formed from a mantellic and youthful source, with a small crustal contribution where $T_{D M}$ ages are 2.35 e $2.21 \mathrm{Ga}$. At the end of the Paleoproterozoic, a strong crustal shortening happened, and a partial melting of isolated and thickening compartments were facilitated, generating some igneous bodies (1.85 and $1.82 \mathrm{Ga}$ ) and Serrote Granite (1.86 Ga), that comes from sources situated between 2.50 and $2.43 \mathrm{Ga}$. At the end of the Mesoproterozoic, the region was marked by taphrogenetic processes, evidenced by the appearance of alkaline magmatism (1.05 Ga), beyond depositional basins, amongst which the one that received the sediments that had originated the supracrustals of Araguaia Belt. Through the inversion in the geodynamic conditions, in the Neoproterozoic, a process of horizontal shortening with crustal thickening and distinct volumetric and spatial melting occurred, which may have generated Matança and Santa Luzia Granites. The Araguaia Belt was built from this tectonic motion. The tectonic mass transport in the Amazonian Craton might have occurred, resulting in the current architecture in the form of imbricate fans.
\end{abstract}

KEYWORDS: Araguaia Belt; geologic evolution; geochronology; single zircon Pb-evaporation; $\mathrm{Sm} / \mathrm{Nd}$.

\footnotetext{
${ }^{1}$ Departamento de Oceanografia e Limnologia, Universidade Federal do Maranhão - UFMA, São Luís (MA), Brasil. E-mail: sharcanjo@ufma.br 2Instituto de Geociências, Faculdade de Geologia, Universidade Federal do Pará - UFPA, Belém (PA), Brasil. E-mails: famatos@ufpa.br; candido@ufpa.br *Autor Correspondente
}

Manuscrito ID 27534. Recebido em: 06/06/2012. Aprovado em: 21/06/2013. 


\section{INTRODUÇÃO}

O Cinturão Araguaia (CA) (Hasui et al. 1980), unidade geotectônica da porção ocidental da Província Estrutural do Tocantins (Almeida et al. 1977, 1981), é uma faixa alongada na direção N-S, com aproximadamente $1.200 \mathrm{~km}$ e largura de até $100 \mathrm{~km}$. Posiciona-se à borda oriental do Cráton Amazônico. Seu flanco leste acha-se recoberto por sedimentos fanerozoicos da Bacia do Parnaíba, e a sudeste, limita-se com Maciço de Goiás (Almeida et al. 1976). A porçâo sul do CA, onde se situa a cidade de Paraíso do Tocantins, incorpora registros litoestruturais importantes para o entendimento da evolução geológica no domínio centro-leste da Província Tocantins (Fig. 1).

As rochas do embasamento e de algumas unidades supracrustais têm sido investigadas, desde meados da década de 1990 (Souza \& Moura 1995, Souza \& Moura 1996, Moura \& Souza 1996, Arcanjo \& Moura 2000, Arcanjo et al. 2001). Os estudos geocronológicos, utilizando o método $\mathrm{Pb}-\mathrm{Pb}$ em zircáo para obtençáo das idades de cristalizaçấo, apontaram idades paleoproterozoicas, para as unidades litoestratigráficas, contrapondo-se à ideia vigente de ser o mesmo um terreno arqueano. Em razáo disso, esse segmento crustal representa um terreno mais novo, o qual teria sido justaposto às rochas arqueanas do Cráton Amazônico durante o Paleoproterozoico (Moura \& Gaudette 1994, Arcanjo \& Moura 2000).

O Complexo Rio dos Mangues (CRM) passou a agrupar gnaisses cálcio-silicáticos e ortognaisses, de composição tonalítica e granodiorítica, estruturados em torno de 2,1 Ga, e como consequência foi proposta uma redução das áreas consideradas como de ocorrência do Complexo Colmeia (Souza \& Moura 1995, Souza 1996, Souza \& Moura 1996, Moura \& Souza 1996).

A Suíte Monte Santo, representada por ortognaisses alcalinos, provavelmente, teve sua gênese ligada a um evento distensivo, que também levou à formaçáo de áreas abatidas e preenchidas por sedimentos, posteriormente deformados, durante o Ciclo Brasiliano, os quais deram origem aos metamorfitos do CA. A idade mesoproterozoica obtida em cristais de zircão de gnaisses sieníticos do corpo de Serra da Estrela (1,01 Ga) (Souza 1996) foi confirmada no corpo de Monte Santo (1,05 Ga) (Arcanjo et al. 2001). Idades Sm/Nd nas rochas alcalinas dos dois corpos, até agora inéditas, são aqui apresentadas.

Este trabalho é uma contribuição ao conhecimento sobre a evoluçáo geológica do embasamento da porçáo sul do $\mathrm{CA}$, considerando, principalmente, as questóes de natureza litoestratigráfica e geotectônica.

\section{CONTEXTO GEOLÓGICO DA REGIÃO DE PARAÍSO DO TOCANTINS}

Na regiáo central do estado do Tocantins, os afloramentos rochosos são restritos e esparsos, possibilitando apenas contato inferido entre as cinco unidades do embasamento (Fig. 2).

O Grupo Rio do Coco (Costa et al. 1983), de idade arqueana $\mathrm{Pb}-\mathrm{Pb}$ em $\mathrm{Zr}$ confirmada (2,6 Ga; Arcanjo 2002), é formado por um núcleo restrito, caracterizado por Barreira (1980) e Barreira \& Dardenne (1981) como uma sequência metavulcano-sedimentar, tipo greenstone belt, dividida em unidade inferior: sedimentos pelíticos e químicos e intercalaçôes de xistos magnesianos; e superior: xistos feldspáticos e rochas máficas. Compreende rochas vulcânicas komatíticas, intercaladas com sedimentos químicos e pelíticos, assentadas sobre um embasamento siálico que é intrudido por álcali-feldspato granitos (Costa et al. 1983).

Os xistos feldspáticos cinza-esbranquiçados apresentam quartzo, plagioclásio, moscovita, flogopita, filmes de sulfetos (pirita e arsenopirita), rutilo, turmalina e clorita, em arranjos granoblásticos nos agregados quartzo-feldspáticos, alternados com leitos lepidoblásticos com micas. Entre os metapelitos se destacam quartzo-mica xistos com ou sem granada de coloração cinza escura, constituídos por quartzo, biotita, moscovita, plagioclásio, granada, epídoto, clorita, calcita, turmalina e opacos. Nestas rochas desenvolve-se bandamento milimétrico e foliação milonítica penetrativa, com feldspatos ocelares, contornados por filmes de minerais micáceos, além quartzo fitado realçando essa feição textural.

A rocha metabásica datada por Arcanjo et al. (2000), na localidade de Monte Santo, pode ser correlacionada à unidade superior da sequência estratigráfica, proposta por Barreira \& Dardene (1981).

O Complexo Rio dos Mangues (CRM) (Costa et al. 1983), estende-se por uma faixa de direção NW-SE, que se inicia próxima a vila de Monte Santo, bifurca para NE, na altura do povoado de Pugmil e segue para sul até a região do Gurupi/TO. É formado por gnaisses tonalíticos, granodioríticos e cálcio-silicáticos migmatizados, com leucossomas granodioríticos associados (Souza 1996), granada biotita paragnaises, ortoquartzitos, granito-gnaisses e anfibolitos subordinados (Costa et al. 1983). Os gnaisses tonalíticos são mesocráticos a melanocráticos, cinza escuros, de granulação média a grossa, compostos por quartzo (25 $35 \%)$, plagioclásio $(25-40 \%)$, microclíneo $(0-5 \%)$, hornblenda $(0-20 \%)$ biotita $(10-25 \%)$, moscovita $(5-$ $20 \%$ ), além de zircấo, sericita, epídoto, titanita, apatita e opacos. Texturalmente, na foliação milonítica destacam-se aglomerados quartzo-feldspáticos, recristalizados, muitas 


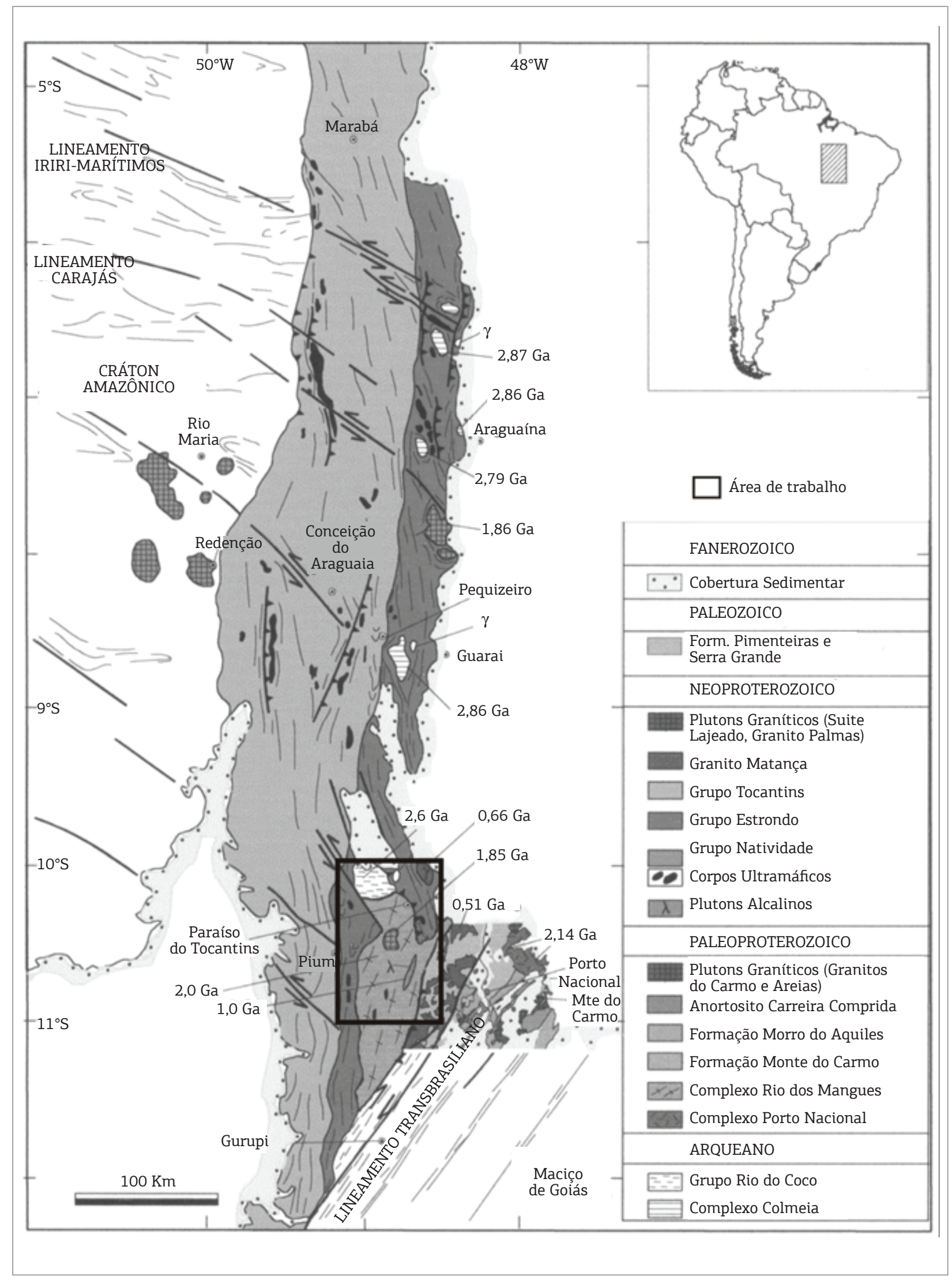

Figura 1. Cinturão Araguaia, seu embasamento e limites com o Cráton Amazônico, Bacia do Parnaíba e Maciço de Goiás (modificado de Alvarenga et al. 2000). A área trabalhada é indicada no retângulo, a oeste da região de Porto Nacional (modificado de Gorayeb 1996). 
vezes alterados, que se alternam com minerais máficos (anfibólio e biotita) orientados, amoldando-se àqueles primeiros, imprimindo um padrão anastomosado.

Os gnaisses granodioríticos, que afloram nas porçôes sudeste e noroeste da área, são mesocráticos, cinzaclaros, compostos por plagioclásio $(40-50 \%)$, quartzo (20 - 35\%), ortoclásio/microclíneo $(8-15 \%)$, biotita $(10-15 \%)$, hornblenda $(0-2 \%)$, bem como epídoto, apatita, zircão e opacos. Um bandamento milimétricocentimétrico é dominante.

Os granada-biotita gnaisses (paraderivados), são leucocráticos, de coloração cinza clara e foliação definida pela orientação de finos cristais sigmoides de quartzo e feldspato, envolvidos por concentrados de biotita, concordantes com o bandamento, desenhado pela alternância de bandas félsicas centimétricas, ricas em agregados quartzo-feldspáticos

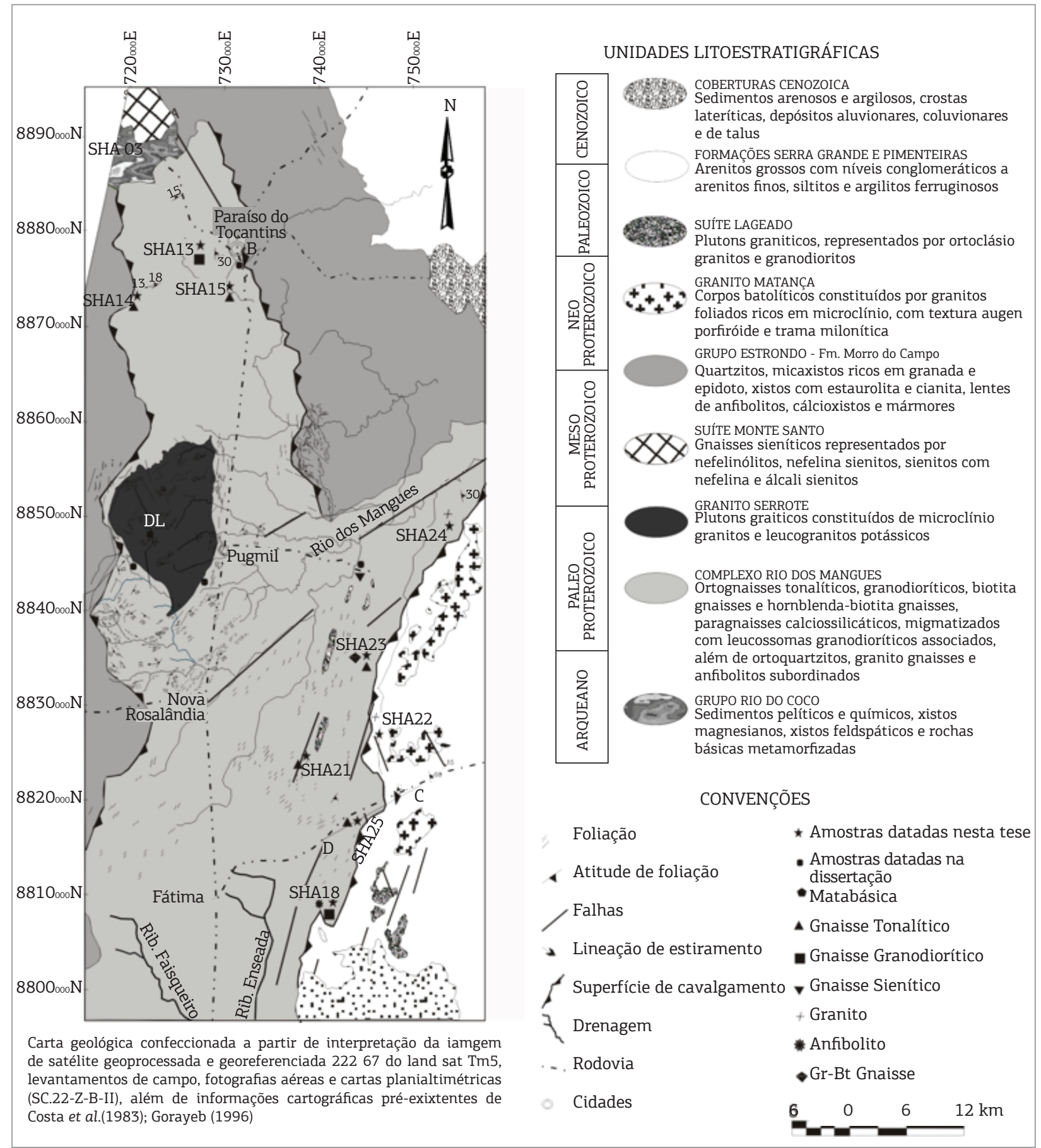

Figura 2. Mapa geológico simplificado da região de Paraíso do Tocantins. 
e máficas com biotita e granada. Mineralogicamente estâo presentes plagioclásio (40\%), quartzo (40\%), biotita $(15 \%)$, granada $(2 \%)$, zircão (traços) sericita e moscovita (minerais em desequilíbrio com a paragênese).

Entremeados aos ortognaisses são encontrados anfibolitos, constituídos por hornblenda (70\%), plagioclásio (15$20 \%$ ), quartzo (10\%), recristalizados e orientados, opacos $(3-5 \%)$, apatita e raros zircóes.

Todas essas rochas, em diferentes graus, estáo migmatizadas e apresentam veios pegmatoides restritos, concordantes com a foliação milonítica que, embora variando localmente, mostra um comportamento regional de orientação NNE a NE com mergulhos médios dominantemente para leste no mapa da Fig. 2.

A migmatizaçáo e a milonitização podem ser compreendidas como processos sincrônicos que aconteceram em episódios de fusóes (mobilizados) em um ambiente geologicamente caracterizado como de fluxo plástico.

$\mathrm{Na}$ porçáo leste da área, dentro do domínio do CRM, afloram restritos ortognaisses de natureza álcali-feldspático granítica e tonalítica, cujos contatos estão encobertos e suas dimensóes são desconhecidas. Os primeiros são leucocráticos, coloração rosa, textura granoblástica, foliação bem evidente e feiçóes micrográficas localizadas. São compostos por microclíneo $(60 \%)$, quartzo $(20-25 \%)$, biotita $(5-7 \%)$, plagioclásio $( \pm 5 \%)$, além de moscovita e sericita secundários, opacos e zircóes. Os gnaisses tonalíticos, são mesocráticos, cinza, bandados, com granulação média e porçôes migmatizadas. A textura milonítica apresenta arranjos pseudogranulares alotriomórficos a hipidiomórficos com cristais subarredondados. Sáo compostos por plagioclásio, andesina $(35-45 \%)$, quartzo $(40 \%)$, microclíneo $(5 \%)$, biotita $(3-5 \%)$, hornblenda $(4 \%)$, zircão e rutilo, titanita e apatita como traços.

Os gnaisses tonalíticos descritos por Costa et al. (1983) na estrada de Chapada de Areia (leste da área de estudo) estão contextualizados no CRM e não correspondem ao Grupo Rio do Coco conforme supunham aqueles autores.

Na porção centro norte do CRM está alojado o Granito Serrote (Costa 1985), um corpo elíptico com eixo maior $(19 \mathrm{~km})$ na direção NNE-SSW. São plútons com tramas augen-porfiroides e miloníticas representados por microclínio granitos e leucogranitos potássicos (Gorayeb 1996). O corpo apresenta foliação incipiente, que se torna mais evidente e com características anastomosadas em suas bordas (Souza 1996). É leucocrático, granulometria média a grossa, nas porçóes centrais e fina, na borda. É porfirítico com fenocristais de microclíneo, plagioclásio e quartzo, orientados e amendoados, imersos em matriz granoblástica fina, representada por quartzo, microclíneo, plagioclásio e em menor quantidade, biotita lamelar, anfibólio e moscovita, fracamente orientada, mas manifestando leve foliação da rocha. Completam a mineralogia, titanita, alanita, zircão, apatita, calcita, epídoto e opacos.

A Suíte Monte Santo (Costa et al. 1983) compreende dois corpos de gnaisses alcalinos que intrudem rochas regionais: Serra da Estrela, encaixado em rochas do CRM e Monte Santo, recoberto em parte pelo Grupo Estrondo. Estas rochas ocorrem sob a forma de lentes inclinadas para sudeste, configurando na interpretação de Costa (1985) um aleitamento tectônico. Entre os litotipos estão nefelinólitos, nefelina sienitos, sienitos com nefelina e álcali-sienitos, retrabalhados por metamorfismo e metassomatismo (Iwanuch 1991). Os gnaisses sieníticos, às proximidades da Vila de Monte Santo são mesocráticos com coloração rosa predominante e variaçóes para cinza. Apresentam granulação média a grossa e são compostos por plagioclásio (15\%), microclíneo $(55 \%)$, quartzo (2\%), moscovita (5\%), biotita $(20 \%)$, além de opacos, zircão e epídoto. A textura é grano-lepidoblástica com orientação de agregados quartzofeldspáticos e bandas milimétricas de biotita. A orientação geral da foliação milonítica é NE-SW e mergulhos baixos da lineação de estiramento para SSW.

O Granito Matança (Costa et al. 1984) sustenta parte da Serra das Cordilheiras, na porção leste da área. Seus contatos, a oeste com o CRM e a leste com o Complexo Porto Nacional e a Formação Morro o Aquiles, são inferidos e tectônicos, por meio de zonas de cisalhamento. De coloração rosada, é rico em microclínio, com textura porfirítica com mega cristais deformados. Composicionalmente varia para álcali-feldspato granito, sienogranito, quartzo monzonito a granodiorítico, que representariam emanaçóes tardias, durante a evoluçáo do corpo maior (Gorayeb 1996).

O padrão regional da foliação, de natureza milonítica, bem como do bandamento gnáissico a ela paralelizado, varia de NW-SE a NE-SW, mantendo um persistente mergulho, da ordem de $20-40^{\circ}$, para leste. As lineaçóes, por sua vez, representadas por minerais estirados, tais como o quartzo, bem como micas, contidas nesses planos, desenham rakes na faixa de $30-40^{\circ}$ e mergulhos preferenciais para SE. Tal organização remete a um contexto regional de nappismo, transposiçôes e imbricaçóes, decorrentes de misturação tectônica das diversas unidades litoestruturais-estratigráficas, com transporte geral de massas no sentido do Cráton Amazônico. A organização estrutural imposta por esses processos formata uma configuração de amêndoas e lentes resultantes principalmente do mecanismo de transposição, uma feição anastomosada, vistas nos mapas em escala regional e de semidetalhe, como por exemplo em Costa (1985) e Gorayeb (1996). Este é, aliás, um aspecto geométrico que se revela desde a escala micro-meso 
das foliações miloníticas até a estruturação mesomacro de alternância de litotipos e mesmo de grupos litológicos. Padrôes estruturais pretéritos ainda podem ser identificados nas amêndoas maiores (Fig. 2).

\section{METODOLOGIA}

As análises pelos métodos de evaporação de $\mathrm{Pb}$ em monocristais de zircão ( $\mathrm{Pb}-\mathrm{Pb}$ em zircão) e $\mathrm{Sm} / \mathrm{Nd}$ (rocha total) foram realizadas no espectrômetro de massa de ionização termal FINNIGAN MAT, modelo 262, do Laboratório de Geologia Isotópica do Instituto de Geociências da Universidade Federal do Pará/Pará-Iso.

Os cristais de zircão foram preferencialmente aqueles da fração não magnética (NM), obtidos com $0^{\circ}$ de inclinação lateral (no separador magnético Frantz Isodynamic). Eventualmente, na ausência dessa fração, foram analisados cristais de zircão da fração magnética $(\mathrm{M})$ a $0^{\circ}$, ou não magnética com $1^{\circ}$ de inclinação lateral. Os procedimentos metodológicos de rotina no Pará-Iso para o método de Pb$\mathrm{Pb}$ em zircão são discutidos em Moura (1992), Macambira et al. (1994) e Arcanjo (2002).

É importante frisar que uma das grandes vantagens operacionais deste método é a determinação da idade aparente ${ }^{207} \mathrm{~Pb} /{ }^{206} \mathrm{~Pb}$ de um único cristal de zircão, em curto espaço de tempo e sem tratamento químico prévio. Ressaltase que o grão de zircão datado é pequeno $(<0,3 \mathrm{~mm})$, não necessitando sofrer purificação ou limpeza de pequenas áreas, sendo possível a eliminação do $\mathrm{Pb}$ de contaminação. Esta metodologia possibilita ainda datar rochas com uma pequena quantidade de cristais de zircão.

A técnica analítica para o método $\mathrm{Sm} / \mathrm{Nd}$ (rocha total), descrita por Kelley (apud Moura 1992) e Hayward (apud Moura 1992) encerra uma grande vantagem no processo de datação, pois o sistema dificilmente é perturbado por eventos geológicos superpostos, em função da pouca mobilidade destes elementos em escala de rocha total. Além disso, as razões $\mathrm{Sm} / \mathrm{Nd}$ são mais elevadas nas rochas ultramáficas do manto em relação a crosta continental, possibilitando que estas rochas sejam datadas, o que dificilmente é conseguido por outro método.

Neste trabalho, os resultados foram discutidos através do modelamento de depleated mantle (DM), proposto por De Paolo (1988) que também distingue os tipos de materiais dos sistemas crosta-manto segundo um fator de fracionamento designado $f_{S m / N d}$ relativo aos meteoritos condríticos. Nesse entendimento, os materiais diferenciados com razão maior que 0,1967 terão f positivo (material mantélico) enquanto serão negativos os de razão menor que este valor médio admitido para os condritos (material crustal).
Segundo o modelo, dentro de um processo de fusão parcial, o magma tem razão $\mathrm{Sm} / \mathrm{Nd}$ sempre mais baixa do que a rocha fonte original e as concentraçôes de $\mathrm{Nd}$ e Sm geralmente são maiores no líquido em comparação à rocha original (Bertotti 2005).

\section{RESULTADOS}

\section{Idades $\mathrm{Pb}-\mathrm{Pb}$ em zircão}

São apresentadas as idades de 10 amostras sendo uma do Grupo Rio do Coco, cinco do CRM, três de ortognaisses intrusivos no CRM e uma do Granito Matança (Tab. 1).

\section{Grupo Rio do Coco}

$\mathrm{O}$ valor médio de $2.618 \pm 14 \mathrm{Ma}$, do gnaisse de natureza metabásica representativo do Grupo Rio do Coco (SHA-03), é interpretado como sendo o da sua idade mínima de cristalização e consequentemente é estendido para essa unidade arqueana.

\section{Complexo Rio dos Mangues}

Os resultados precisos e com erros baixos, obtidos no gnaisse tonalítico (SHA-14a) de $2.065 \pm 3$ Ma e no gnaisse granodiorítico (SHA-13b), de $2.066 \pm 6$ Ma estáo sendo interpretados como idades mínimas de cristalização dos protólitos ígneos e que define a idade do Complexo Rio dos Mangues (CRM). A idade média final de $2.054 \pm 4 \mathrm{Ma}$ obtida para o gnaisse tonalítico (SHA-15a), é provavelmente a idade mínima de cristalização da rocha, a qual poderia ser ainda mais velha, uma vez que os cristais analisados são magnéticos a $1^{\circ}$, e assim, susceptíveis de fornecerem resultados inferiores.

As análises dos cristais do gnaisse tonalítico (SHA-25a) mostram padrão regular e crescente de distribuição das idades, o que pode simbolizar uma linha de mistura entre aquelas que se iniciam em torno de $550 \mathrm{Ma}$ e atingem valores ligeiramente superiores a $2.300 \mathrm{Ma}$. A idade média de $546 \pm 4 \mathrm{Ma}$, obtida em duas etapas de temperatura $\left(1.500\right.$ e $\left.1.550^{\circ} \mathrm{C}\right)$, de um dos cristais, é similar e consistente com a idade de cristalização do Granito Matança, que ocorre a poucos quilômetros a leste deste gnaisse. Em outro cristal obteve-se uma idade média de $2.058 \pm 6 \mathrm{Ma}$, que poderia representar sua idade mínima de cristalização, próxima da idade obtida para zircóes de gnaisses do CRM. Contudo, por serem os cristais moderadamente metamíticos, esta idade está sendo vista com cautela, uma vez que poderia ser um pouco mais elevada. Outro cristal analisado forneceu uma idade média de $2.127 \pm 9 \mathrm{Ma}$, que poderia ser a idade mínima de cristalização do protólito ígneo que 
gerou este gnaisse tonalítico. Neste caso, apesar da idade ser um pouco mais antiga do que as demais obtidas para o grupo de rochas do CRM, assemelha-se, àquelas encontradas em granulitos da região vizinha à Porto Nacional $(2.125 \pm 3$ e $2.153 \pm 1$ Ma, Gorayeb, Moura \& Arcanjo 2000), interpretadas como idades mínimas de cristalização para aqueles corpos. As idades com valores maiores, obtidas em temperaturas mais elevadas, provavelmente representam algum componente herdado e por ser extremamente migmatizado e estar próximo de uma zona de falha que separa o CRM do Granito Matança, compóem fatores desfavoráveis à obtenção de dados geocronológicos precisos.

A determinação das idades obtidas para o gnaisse granodiorítico (SHA-18d 614 a $2.260 \mathrm{Ma}$ ) foi comprometida em função da localização deste corpo, próximo da zona de contato do CRM com o Granito Matança. Por fazer parte do domínio do CRM, é possível que, a idade de $2.086 \pm 16 \mathrm{Ma}$, obtida a uma temperatura elevada, em apenas um dos cristais, sem metamitização, represente a idade de cristalização para esta rocha. À semelhança do gnaisse tonalítico (SHA-25a), as idades mais antigas registradas, acima de $2.200 \mathrm{Ma}$, devem representar os valores de componentes crustais mais antigos (herdados). $\mathrm{O}$ valor em torno de 600 Ma pode representar os reflexos do sobrecrescimento, ocorrido a partir do Neoproterozoico e facilitado por processos magmáticos relacionados a colocação do Granito Matança.

\section{Ortognaisses intrusivos no Complexo Rio dos Mangues}

Em um grupo de quatro grãos de zircão do gnaisse tonalítico (SHA-21), as idades ${ }^{207} \mathrm{~Pb} /{ }^{206} \mathrm{~Pb}$, situaram-se entre $837 \pm 42$ e $736 \pm 46 \mathrm{Ma}$. Em um outro cristal, metamítico, a idade média final foi de $1.100 \pm 24 \mathrm{Ma}$. Diferentemente destes dois primeiros conjuntos de idades, outro cristal, apresentou idade média de $1.887 \pm 20 \mathrm{Ma}$. Cada um destes resultados merece uma avaliação individual. Seu

Tabela 1. Resultados gerais e características dos cristais de zircão nas amostras analisadas pelo método $\mathrm{Pb}-\mathrm{Pb}$ em zircão

\begin{tabular}{|c|c|c|c|c|c|c|c|}
\hline Unidade & Amostra & Litotipo & $\begin{array}{l}\text { Cristais Zr } \\
\text { analisados }\end{array}$ & $\begin{array}{l}\text { Cristais } \mathrm{Zr} \\
\text { atendidos }\end{array}$ & $\begin{array}{c}\text { Fração } \\
\text { Magnética }\end{array}$ & Características dos cristais $\mathbf{Z r}$ & $\begin{array}{l}\text { Idade } \\
\text { (Ma) }\end{array}$ \\
\hline \multirow[t]{9}{*}{$\begin{array}{l}\text { Granito } \\
\text { Matança }\end{array}$} & SHA-22 & $\begin{array}{c}\text { Gnaisse } \\
\text { Monzogranítico }\end{array}$ & 4 & 1 & $1^{\circ} \mathrm{NM}$ & $\begin{array}{l}\text { Prismáticos euédricos, tamanho } 2 / 1, \\
\text { transparentes, amarelados, algumas } \\
\text { inclusões e fraturas internas }\end{array}$ & $547 \pm 6$ \\
\hline & SHA-21 & $\begin{array}{l}\text { Gnaisse } \\
\text { Tonalítico }\end{array}$ & 13 & & $0^{\circ} \mathrm{M}$ & $\begin{array}{l}\text { Subédricos, subarredondados a } \\
\text { anédricos, tamanho } 2 / 1 \text { e } 3 / 1 \text {. } \\
\text { Fraturados, geminados, translúcidos, } \\
\text { amarelados, e alguns metamíticos. }\end{array}$ & $837 \pm 42$ \\
\hline & SHA-23a & $\begin{array}{l}\text { Gnaisse } \\
\text { Tonalítico }\end{array}$ & 13 & & $1^{\circ} \mathrm{M}$ & $\begin{array}{c}\text { Subédricos, subangulosos a sub- } \\
\text { arredondados, prismáticos, tamanho } \\
\text { 2/1, } 3 / 1 \text { e } 4 / 1 \text {, transparentes, } \\
\text { castanhos, metamíticos. }\end{array}$ & $\begin{array}{l}1.850 \pm 7 \\
(547 \pm 7)\end{array}$ \\
\hline & SHA-24 & $\begin{array}{l}\text { Gnaisse Álcali } \\
\text { Feldspático } \\
\text { Granítico }\end{array}$ & 4 & 1 & $0^{\circ} \mathrm{M}$ & $\begin{array}{l}\text { Subédricos, subangulosos, } \\
\text { prismáticos, tamanho } 2 / 1 \mathrm{e} \\
\text { 3/1, transparentes, amarelados, } \\
\text { inclusões. }\end{array}$ & $1.823 \pm 3$ \\
\hline & SHA-13b & $\begin{array}{c}\text { Gnaisse } \\
\text { Grandiorítico }\end{array}$ & 6 & 3 & $\mathrm{O}^{\circ} \mathrm{NM}$ & $\begin{array}{l}\text { Prismáticos, euédricos, tamanho } 2 / 1 \\
\text { e } 3 / 1 \text {, angulosos a subangulosos, } \\
\text { transparentes, amarelados }\end{array}$ & $2.066 \pm 6$ \\
\hline & SHA-14a & $\begin{array}{l}\text { Gnaisse } \\
\text { Tonalítico }\end{array}$ & 6 & 6 & $0^{\circ} \mathrm{NM}$ & $\begin{array}{l}\text { Prismáticos, euédricos, tamanho } \\
2 / 1 \text { e } 3 / 1 \text {, angulosos, límpidos, } \\
\text { transparentes, fraturas internas }\end{array}$ & $2.065 \pm 3$ \\
\hline & SHA-15a & $\begin{array}{l}\text { Gnaisse } \\
\text { Tonalítico }\end{array}$ & 4 & 2 & $1^{0} \mathrm{M}$ & $\begin{array}{c}\text { Pouco translúcidos e amarelados, } \\
\text { subarredondadas, curtos, subédricos } \\
\text { e tamanho } 2 / 1\end{array}$ & $2.054 \pm 4$ \\
\hline & SHA-25a & $\begin{array}{l}\text { Gnaisse } \\
\text { Tonalítico }\end{array}$ & 15 & & $\mathrm{O}^{\circ} \mathrm{NM}$ & $\begin{array}{c}\text { Prismáticos longos, euédricos, } \\
\text { angulosos a sub-angulosos, tamanho } \\
\text { 3/1 a } 4 / 1 \text {, transparentes, amarelados. } \\
\text { Núcleo em geral anédrico, e ainda } \\
\text { subédrico a euédrico. }\end{array}$ & $\begin{array}{c}2.127 \pm 9 \\
(2.058 \pm 6)\end{array}$ \\
\hline & SHA-18d & $\begin{array}{c}\text { Gnaisse } \\
\text { Granodiorítico }\end{array}$ & 6 & & $1^{\circ} \mathrm{M}$ & $\begin{array}{l}\text { Subédricos, subarredondados a } \\
\text { subangulosos, tamanho } 2 / 1 \text { e } 3 / 1 \text {, } \\
\text { metamíticos }\end{array}$ & $2.086 \pm 16$ \\
\hline $\begin{array}{l}\text { Grupo Rio } \\
\text { do Coco }\end{array}$ & SHA-03 & Metabásica & 8 & 3 & $0^{\circ} \mathrm{NM}$ & $\begin{array}{l}\text { Longos, euédricos a subédricos, } \\
\text { relação comprimento/ largura 3/1, } \\
\text { transparentes, amarelados }\end{array}$ & $2.618 \pm 14$ \\
\hline
\end{tabular}

Zr: zircão; M: magnético; NM: não magnético. 
posicionamento geográfico a desfavorece geocronologicamente pois situa-se tanto próximo da Suíte Monte Santo, como do batólito Matança. O valor de 1.100 Ma de um dos grãos de zircão pode ter tido influência direta dos efeitos térmicos da colocação das rochas alcalinas (1.001 $\pm 86 \mathrm{Ma}$, Arcanjo \& Moura 2000). O valor de $1.887 \pm 20$ Ma deve representar uma idade de crosta herdada e, neste caso, possivelmente, uma idade mínima de cristalização, associada ao CRM. Por haver uma grande quantidade de zircóes com idades que se situam entre $883 \pm 6$ e $762 \pm$ $6 \mathrm{Ma}$, é mais provável que a idade de $837 \pm 42 \mathrm{Ma}$, possa indicar a idade mínima de cristalização para este gnaisse tonalítico, que no caso seria intrusivo no CRM. Esta idade é similar à idade de cristalização de $856 \pm 13 \mathrm{Ma}$ obtida por Pimentel et al. (2000), para gnaisses tonalíticos no Arco Magmático de Goiás, o que abre perspectivas para novas investigaçóes, buscando melhor caracterizar esse evento nessa região.

Idades bastante variáveis foram reveladas entre os cristais de zircão do gnaisse tonalítico (SHA-23a). Em um dos cristais, a idade média foi de $1.850 \pm 7 \mathrm{Ma}$ e em outro, de $547 \pm 7 \mathrm{Ma}$. É possível que este último valor represente a idade de um cristal de zircáo contemporâneo à cristalização do Granito Matança, posto que a amostra tomada se situa próxima ao mesmo. Por outro lado, a idade de $1.850 \pm 7 \mathrm{Ma}$ pode ser a que mais se aproxime da idade mínima de cristalização do gnaisse tonalítico.

O gnaisse álcali-feldspático granítio (SHA-24) pesar de encontrar-se próximo à zona de contato com o Granito Matança, não registrou idades ao redor de $550 \mathrm{Ma}$, conforme foi constatado nos outros corpos alinhados à sudeste. É possível que sua idade, de $1.823 \pm 3 \mathrm{Ma}$ corresponda a uma idade mínima de cristalizaçáo e relacionada ao CRM ou alternativamente, que represente a idade de um corpo contemporâneo ao Granito Serrote e, neste caso, intrusivo no CRM.

\section{Granito Matança}

Foram obtidas idades de $1.009 \pm 6 \mathrm{Ma}, 721 \pm 16 \mathrm{Ma}$, $606 \pm 6 \mathrm{Ma}$ e $547 \pm 6 \mathrm{Ma}$ nos cristais de zircão do gnaisse monzogranítico (SHA-22). Esta última, representa um valor compatível com a idade mínima de cristalização do Granito Matança e uma possível contemporaneidade reforçada pela proximidade deste corpo com aquele batólito granítico, podendo até mesmo representar uma fácies de borda do mesmo.

\section{Sm/Nd (Rocha Total)}

O método $\mathrm{Sm} / \mathrm{Nd}$ em rocha total é empregado sobretudo na determinação, baseada em idades modelo, do tempo de residência crustal das rochas analisadas, o qual pode ser o reflexo do tempo de diferenciaçáo manto-crosta ou simplesmente do tempo de geração de crosta. Estas informações são fundamentais para o entendimento da origem, evolução e relaçôes espaço-temporais entre os gnaisses do embasamento do CA. Para uma melhor visualização dos dados $\mathrm{Sm} / \mathrm{Nd}$ elaborou-se um diagrama com idades modelo (Fig. 3), onde são plotados os campos do CA e regióes vizinhas.

Foram datadas 12 amostras pelo método $\mathrm{Sm} / \mathrm{Nd}$ (rocha total) sendo três do CRM, três do Granito Serrote, três da Suíte Monte Santo e três intrusivas no CRM (Tab. 2).

\section{Complexo Rio dos Mangues}

As idades modelo para os gnaisses tonalíticos, foram de 2,21 e 2,25 Ga, com valores das razóes ${ }^{147} \mathrm{Sm} /{ }^{144} \mathrm{Nd}$ de 0,1011 e 0,1171 e $_{\mathrm{Sm}_{\mathrm{m} / \mathrm{Nd}}} \mathrm{de}-0,486$ e $-0,405$, respectivamente. A idade modelo do gnaisse granodiorítico foi de $2,35 \mathrm{Ga}$. Os valores da razão ${ }^{147} \mathrm{Sm} /{ }^{144} \mathrm{Nd}$ e do $\mathrm{f}_{\mathrm{Sm} / \mathrm{Nd}}$ são de 0,8531 e -0,566, respectivamente. À exceção do gnaisse granodiorítico que se apresenta levemente fracionado, os demais se encontram dentro do intervalo normal de fracionamento, entre 0,09 e 0,125 , conforme sugerido por Sato \& Siga Jr. (2000). Em consequência do fator fracionamento que se situa abaixo do limite inferior do intervalo proposto, também a razão ${ }^{147} \mathrm{Sm} /{ }^{144} \mathrm{Nd}$ desta amostra $(-0,566)$ escapa um pouco ao intervalo aceitável que é de $-0,45 \pm 10$, conforme discutido por aqueles autores.

\section{Granito Serrote}

As amostras datadas do granito Serrote forneceram idades modelo $\mathrm{T}_{\mathrm{DM}}$ 2,43 e 2,50 Ga. Em duas das três amostras datadas, os valores do fator $\mathrm{f}_{\mathrm{Sm} / \mathrm{Nd}}$, de $-0,617$ e $-0,560$, com a razão ${ }^{147} \mathrm{Sm} /{ }^{144} \mathrm{Nd}$ de 0,07542 e 0,08656 , respectivamente, denotam certo fracionamento e uma das amostras apresentase dentro dos limites aceitáveis de fracionamento químico do sistema $\mathrm{Sm} / \mathrm{Nd}$, fornecendo os valores de $-0,500$ e 0,09831, respectivamente para o $\mathrm{f}_{\mathrm{Sm} / \mathrm{Nd}}$ e para a razão ${ }^{147} \mathrm{Sm} /{ }^{144} \mathrm{Nd}$.

\section{Suite Monte Santo}

Foram datados dois gnaisses sieníticos do corpo de Monte Santo e um do corpo da Serra da Estrela. As idades modelo variaram entre 1,70 e 1,49 Ga. $O$ fator $\mathrm{f}_{\mathrm{Sm} / \mathrm{Nd}}$ para uma das amostras é -0,669 e a razão ${ }^{147} \mathrm{Sm} /{ }^{144} \mathrm{Nd}, 0,06515$, mostrando ter havido fracionamento químico do $\mathrm{Sm} / \mathrm{Nd}$. Os valores mais precisos do fator $\mathrm{f}_{\mathrm{Sm} / \mathrm{Nd}}$ e da razão ${ }^{147} \mathrm{Sm} /{ }^{144} \mathrm{Nd}$ foram encontrados para o gnaisse sienítico da Serra da Estrela (-0,467 e 0,10482 ) coerentes com o intervalo aceitável de fracionamento químico.

\section{Ortognaisses intrusivos no Complexo Rio dos Mangues}

O gnaisse tonalítico (SHA-21, $837 \pm 42 \mathrm{Ma}$ ), forneceu uma idade modelo $\mathrm{T}_{\mathrm{DM}} 1,83 \mathrm{Ga}$, com valor de $\varepsilon_{\mathrm{Nd}(\mathrm{T}=084 \mathrm{Ga})}$ 
de -6,20. O fator $\mathrm{f} S \mathrm{~m} / \mathrm{Nd}$, é - 0,402 e a razão ${ }^{147} \mathrm{Sm} /{ }^{144} \mathrm{Nd}$, 0,11768. O gnaisse tonalítico (SHA-23a, $1.850 \pm 7 \mathrm{Ma}$ ), forneceu uma idade modelo $\mathrm{T}_{\mathrm{DM}} 2,78 \mathrm{Ga}$ e um $\varepsilon_{\mathrm{Nd}(\mathrm{T}=1,85 \mathrm{Ga} .)}$ de -9,55. Conforme já apresentado, uma idade alternativa a esta, poderia também indicar uma idade de cristalização para a rocha, com valor de $547 \pm 7 \mathrm{Ma}$, que seria contemporânea ao Granito Matança. Se utilizado este valor, o $\varepsilon_{\mathrm{Nd}(\mathrm{T})}$ teria variação para $-26,06$. A razão ${ }^{147} \mathrm{Sm} /{ }^{144} \mathrm{Nd}$ é de 0,09788 e o fracionamento $\mathrm{f}_{\mathrm{Sm} / \mathrm{Nd}}$ é de $-0,502$. O gnaisse álcali-feldspático granítico (SHA-24, $1.823 \pm 3 \mathrm{Ma}$ ) apresentou idade modelo $\mathrm{T}_{\mathrm{DM}} 3,25 \mathrm{Ga}$. $\mathrm{O} \varepsilon_{\mathrm{Nd}(\mathrm{T}=1.82 \mathrm{Ga})}$ dessa rocha foi negativo e igual a $-13,65$. Por ter idade modelo $T_{D M}$ mais elevada que todas as outras rochas estudadas na região poder-se-ia supor até mesmo que este gnaisse tivesse sofrido algum evento de fracionamento químico. Porém, esta interpretação não é sustentada pelos valores do $\mathrm{f}_{\mathrm{Sm} / \mathrm{Nd}}$, de - 0,414 , nem tão pouco pela razão ${ }^{147} \mathrm{Sm} /{ }^{144} \mathrm{Nd}$, de 0,11533 , valores estes coerentes para o fracionamento da rocha.

\section{EVOLÇÃO GEOLÓGICA}

Os resultados geocronológicos (Tab. 3) admitem algumas consideraçóes sobre a evolução geológica da região enfocada.

Os vestígios mais antigos de uma crosta continental, na porção sul do CA, são formados por sequências vulcanosedimentares que evoluíram em ambiente geológico semelhante aos greenstone belts arqueanos (Grupo Rio do Coco 2,6 Ga). Nesse contexto, protólitos do Granito Serrote $\left(\mathrm{T}_{\mathrm{DM}} 2,43-2,50 \mathrm{Ga}\right)$, podem assinalar mistura de fontes daquela crosta arqueana com um terreno mais novo (CRM $\left.\mathrm{T}_{\mathrm{DM}} 2,35-2,21 \mathrm{Ga}\right)$.

O segmento localizado a leste fornece indícios de ter existido uma crosta mais antiga que 3,25 Ga, (SHA-24) que seria a fonte das rochas graníticas. Possivelmente esta crosta teria se misturado com protólitos de rochas mais jovens $(2,21-2,35 \mathrm{Ga})$, originando um valor intermediário de 2,78 Ga (SHA-23a).

Como modelo evolutivo para agrupar estes resultados, individualiza-se, no Paleoproterozoico, três principais acontecimentos:

Primeiramente sugere-se a existência de núcleos siálicos separados por uma crosta oceânica de expressão desconhecida e a ocorrência de eventos vulcano-plutônicos e tectônicos $(2,0-2,35 \mathrm{Ga})$. A reciclagem dessa crosta oceânica pretérita, em interação com os núcleos vulcânicos, teria gerado rochas de composiçôes tonalítica, trondjhemítica e granodiorítica (TTG), associadas ao aparecimento de platôs oceânicos, semelhante aos arcos magmáticos, relacionados a instabilidades mantélicas e ao funcionamento

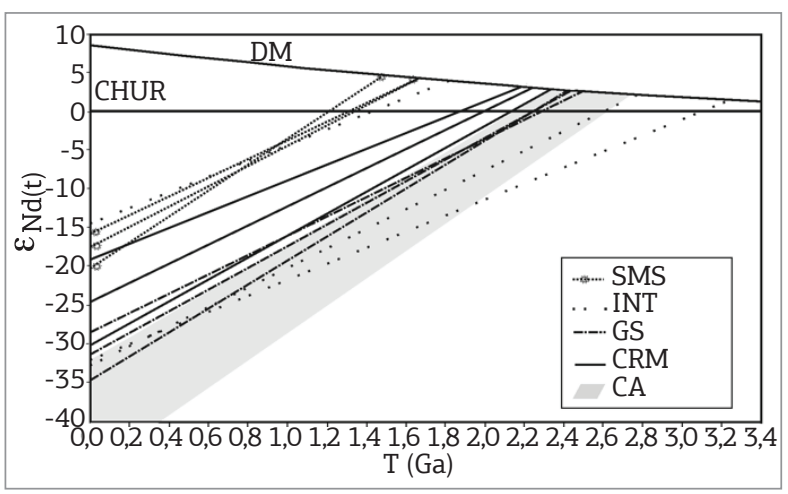

Figura 3. Diagrama representando as idades modelo para rochas do Complexo Rio dos Mangues (CRM), Granito Serrote (GS), Suíte Monte Santo (SMS) e rochas intrusivas no Complexo Rio dos Mangues (INT). O campo do Cráton Amazônico (CA) é baseado em idades modelo Sm-Nd de Sato \& Tassinari (1997). A curva do Manto Empobrecido (DM) segue o modelo de De Paolo (1981).

Tabela 2. Dados Sm-Nd para rochas do Complexo Rio dos Mangues, Granito Serrote, Suite Monte Santo e rochas intrusivas no Complexo Rio dos Mangues

\begin{tabular}{c|c|c|c|c|c|c|c|c|c|c}
\hline Amostra & Rocha & Idade $^{*}$ & Sm & $\mathbf{N d}$ & $\mathbf{S m} / \mathbf{N d}$ & $f_{\text {Sm/Nd }}$ & ${ }^{147} \mathbf{S m} /{ }^{144} \mathbf{N d}$ & ${ }^{143} \mathbf{N d} /{ }^{144} \mathbf{N d}$ & $\varepsilon_{(t)}$ & $\mathbf{T}_{\text {DM }}$ \\
\hline SHA/25a & Gn Tn & 2.12 & 7,66 & 39,55 & 0.194 & $-0,405$ & 0,1171 & 0,511649 & 2,40 & 2,21 \\
\hline SHA/14a & Gn Tn & 2.06 & 4,2 & 25,09 & 0,167 & $-0,486$ & 0,1011 & 0,511385 & 0,86 & 2,25 \\
\hline SHA/13b & Gn Grd & 2.06 & 2,42 & 17,15 & 0,141 & $-0,566$ & 0,08531 & 0,511074 & $-1,04$ & 2,35 \\
\hline DL-12 & Gr Serrote & 1.86 & 5,07 & 40,67 & 0,125 & $-0,617$ & 0,07542 & 0,510847 & $-6,01$ & 2,43 \\
\hline DL-07 & Gr Serrote & 1.86 & 4,78 & 33,42 & 0,143 & $-0,560$ & 0,08656 & 0,511024 & $-5,21$ & 2,43 \\
\hline DL-15 & Gr Serrote & 1.86 & 7,25 & 44,56 & 0,163 & $-0,500$ & 0,09831 & 0,511158 & $-5,41$ & 2,50 \\
\hline CM/60 & Gn Sn & 1.05 & 1,15 & 10,64 & 0,108 & $-0,669$ & 0,06515 & 0,511595 & $-2,52$ & 1,49 \\
\hline CM/61 & Gn Sn & 1.05 & 0,92 & 5,86 & 0,157 & $-0,516$ & 0,09516 & 0,511741 & $-3,74$ & 1,67 \\
\hline SH33 & Gn Sn & 1.01 & 0,74 & 4,3 & 0,172 & $-0,467$ & 0,10482 & 0,511827 & $-4,06$ & 1,70 \\
\hline SHA/21 & Gn Tn & 0.84 & 9,37 & 48,16 & 0,195 & $-0,402$ & 0,11768 & 0,511887 & $-6,20$ & 1,83 \\
\hline SHA/23a & Gn Tn & 1,85 & 4,28 & 26,47 & 0,162 & $-0,502$ & 0,09788 & 0,510948 & $-6,86$ & 2,78 \\
\hline SHA/24 & Álc-Fds Gr & 1.82 & 2,69 & 14,1 & 0,191 & $-0,414$ & 0,11533 & 0,510978 & $-13,65$ & 3,25 \\
\hline
\end{tabular}

*Idade $\mathrm{Pb}$ - $\mathrm{Pb}$ em zircão em Giga-anos (Ga) utilizada como referência para o cálculo de $\varepsilon_{\mathrm{Nd}(\mathrm{t})}$. A idade Pb-Pb em zircão do Granito Serrote é de Sousa \& Moura (1996). As idades $T_{D M}$ são informadas em Giga-anos. 
de plumas. Esse é um quadro comum em terrenos paleoproterozoicos, do Gondwana Ocidental. Confirmam essa situação, o Bloco Granja, no Domínio Médio Coreaú/ Província Borborema (Neves 2003), cujos processos litogenéticos aconteceram ao longo do Sideriano (2,30 - 2,35 Ga); o Domínio Ceará Central, representado pelos orto e paragnáisses de Forquilha; os domínios do Cráton São Luís e Bloco Parnaíba, no Riaciano (2,22 - 2,05 Ga); a borda sul do Cráton São Luis (2,15 e 2,07 Ga) (Basei et al. 2010, Gaudette et al. 1993, Palheta et al. 2009, Gorayeb et al. 1999, Klein \& Moura 2001); várias outras porções da Província Borborema (Brito Neves et al. 2000, Brito Neves 2003, Van Schmus et al. 2008, Arthaud et al. 2008) e mesmo os domínios do Cráton Amazônico, no Escudo das Guianas, como relatado por Ledru et al. (1994), Delor et al. (2003) e Almeida et al. (2008). Basaltos derivados de magmas toleíticos e calcioalcalinos, provenientes de fontes mantélicas, estudados por Gorayeb (1996), na região de Porto Nacional, complementariam o modelo inicialmente aludido, representando antigos platôs meso-oceânicos. $\mathrm{Na}$ área objeto desse estudo talvez eles não mais se encontrem em razão da expressiva taxa de erosão.

O segundo acontecimento retrata as colagens tectônicas $(2,21 \mathrm{Ga})$, com o envolvimento de subducçôes facilitando o desaparecimento dos segmentos crustais oceânicos e a amalgamação dos antigos platôs meso-oceânicos. Nesse período, teriam sido gerados produtos sedimentares e arcos magmáticos.
Colisōes, imbricamentos e cavalgamentos contribuíram para a gnaissificação das rochas ígneas e a implantação de marcantes feições tectônicas (NNE-SSW), com expressão na porção norte do Maciço de Goiás (Cinturão de Cisalhamento Tocantins). Durante o processo colisional (2,0 Ga), estes terrenos teriam sido lançados sobre a borda oriental do Cráton Amazônico, marcando o metamorfismo no CRM. Os processos de colisão e amalgamação não aconteceram simultaneamente de acordo com a variabilidade expressiva das idades no CRM. Os estudos isotópicos indicaram ter havido mistura de fontes (crustal e mantélica) conforme mostraram os valores positivos e negativos de $\varepsilon_{\mathrm{Nd}}$. As idades modelo sugerem a participação de crosta formada predominantemente no início do Paleoproterozoico, com menor envolvimento de crosta arqueana.

No terceiro acontecimento, encerrando o Paleoproterozoico, desapareceram os domínios oceânicos e projetaram-se injeçóes de plútons graníticos (Granito Serrote/1,86 Ga, Gnaisse Cantáo/1,85 Ga e pequenos corpos ígneos/1,85 e 1,82 Ga). O Gnaisse Cantão, comparado aos granitoides do Cráton Amazônico (Moura \& Gaudette 1993, Moura \& Gaudette 1999) poderia ser uma expressão dessa granitogênese no norte do CA, discussão que foge ao escopo desse trabalho.

No Neoproterozoico, a porção oriental do CA registrou o desaparecimento dos protólitos arqueanos, recobertos

Tabela 3. Síntese dos resultados das datações ( $\mathrm{Pb}-\mathrm{Pb}$ em zircão e $\mathrm{Sm} / \mathrm{Nd}$ ) das rochas estudadas na região de Paraíso do Tocantins

\begin{tabular}{|c|c|c|c|c|c|}
\hline $\begin{array}{l}\text { Unidade } \\
\text { Litoestratigráfica }\end{array}$ & Litotipo & Amostra & Idades Pb-Pb em Zircão (Ma) & Idades Modelo (Ga) & $\varepsilon_{\mathrm{Nd}(\mathrm{T})}$ \\
\hline Granito Matança & $\begin{array}{c}\text { Gnaisse } \\
\text { Monzogranítico }\end{array}$ & SHA-22 & $547 \pm 6$ & & \\
\hline \multirow[t]{2}{*}{ Intrusiva } & Gnaisse Tonalítico & SHA-21 & $837 \pm 42$ & 1,83 & $-6,20$ \\
\hline & Gnaisse Sienítico & SHA-02 & $1.051 \pm 17$ & & \\
\hline Suíte Monte & Gnaisse Sienítico & CM-60 & 1.050 & 1,49 & $-2,52$ \\
\hline \multirow[t]{2}{*}{ Santo } & Gnaisse Sienítico & CM-61 & 1.050 & 1,67 & $-3,74$ \\
\hline & Gnaisse Sienítico & SHA-33 & $1.001 \pm 86$ & 1,70 & $-4,06$ \\
\hline \multirow[t]{3}{*}{ Intrusivas } & Gnaisse Tonalítico & SHA-23a & $\begin{array}{l}1.850 \pm 7 \\
(547 \pm 7)\end{array}$ & 2,78 & $\begin{array}{c}-9,55 \\
(-26,06)\end{array}$ \\
\hline & $\begin{array}{c}\text { Gnaisse Álcali - } \\
\text { Feldspático Granítico }\end{array}$ & SHA-24 & $1.823 \pm 3$ & 3,25 & $-13,65$ \\
\hline & Granito & DL-07 & $1.861 \pm 41$ & 2,43 & $-5,21$ \\
\hline \multirow[t]{3}{*}{ Granito Serrote } & Granito & DL-12 & $1.861 \pm 41$ & 2,43 & $-6,01$ \\
\hline & Granito & DL-15 & $1.861 \pm 41$ & 2,50 & $-5,41$ \\
\hline & $\begin{array}{c}\text { Gnaisse } \\
\text { Granodiorítico }\end{array}$ & SHA-13b & $2.066 \pm 6$ & 2,35 & $-1,04$ \\
\hline Complexo Rio & Gnaisse Tonalítico & SHA-15a & $2.054 \pm 4$ & & \\
\hline \multirow[t]{3}{*}{ dos Mangues } & Gnaisse Tonalítico & SHA-14a & $2.065 \pm 3$ & 2,25 & 0,86 \\
\hline & $\begin{array}{c}\text { Gnaisse } \\
\text { Granodiorítico }\end{array}$ & SHA-18d & $2.086 \pm 16$ & & \\
\hline & Gnaisse Tonalítico & SHA-25a & $\begin{array}{l}2.127 \pm 9 \\
(2.058 \pm 6)\end{array}$ & 2,21 & $\begin{array}{c}2,40 \\
(1,78)\end{array}$ \\
\hline $\begin{array}{l}\text { Grupo Rio } \\
\text { Do Coco }\end{array}$ & Metamáfica & SHA-03 & $2.618 \pm 14$ & & \\
\hline
\end{tabular}

(1) Arcanjo \& Moura (2000); (2) Sousa \& Moura (1996). 
por cavalgamento das unidades paleoproterozoicas, com larga ocorrência no entorno do Granito Matança.

Um longo período de estabilização configurou o desenho final do Supercontinente Atlântica (Mabessone 2002) e se estendeu até $1,1 \mathrm{Ga}$, com rifteamentos, afastamento de massas e desenvolvimento de um oceano bem marcado no domínio das faixas Farusiana e Dahomeana (Palheta 2001), na periferia da massa cratônica São Luís/Oeste Africano. O fechamento desse novo domínio oceânico, com repercussōes na plataforma sulamericana, deu-se por meio da colagem brasiliana-panafricana, em três estágios principais $(650$ - 600, 580 - 560 e 540 - $500 \mathrm{Ma})$ o último dos quais adentrando o Ordoviciano (Basei et al. 2010).

No segmento sul do CA a distensão foi sentida através da discreta tentativa de fragmentação intracratônica, expressa pelo magmatismo alcalino da Suíte Monte Santo e na região do Gurupi, divisa Pará-Maranhão, pelo Nefelina Gnaisse de Boca Nova (idade $\mathrm{Rb} / \mathrm{Sr}$ em rocha total 723 Ma; Villas 1982, Palheta 2001). Vulcanismo fissural e plutonismo alcalino, entre o Neoproterozoico (650 Ma) e o início do Ordoviciano também são citados por Brito Neves (1998) e Brito Neves et al. (1999), como associados ao aparecimento de bacias que controlaram a deposição do Grupo Jaibaras, ao longo do Lineamento Transbrasiliano.

Este processo de rifteamento, provavelmente, foi responsável pela formação da bacia submeridiana que acolheu as rochas que originaram o Supergrupo Baixo Araguaia (Abreu 1990, Arcanjo \& Moura 2000). Abreu (1990) sugere que, concomitantemente ao aporte de sedimentos, estaria havendo subsidência, movimentos distensivos e colocação de magmas máfico-ultramáficos, evoluindo para a formação de um proto-rifte, com posterior oceanização, que mesmo inexpressiva, permitiu a formação de um complexo ofiolítico, razoavelmente descrito (Paixão et al. 2008, Kotschoubey et al. 2005, Cruz \& Gorayeb 2008, Gorayeb et al. 2011) a exemplo do bem conhecido Complexo de Bou Azzer, no Marrocos, à borda oriental do Cráton Oeste Africano (Leblanc 1981, Hadi et al. 2010).

Regionalmente, a leste, nos arredores de Monte do Carmo e Porto Nacional, o embaciamento confirma-se pelos metassedimentos do Grupo Natividade. Esse é o quadro definido quando da fragmentação do Supercontinente Rodínia, com geração de pulsos de magmatismo alcalino e numerosa incidência de complexos plutônicos (augita sienitos, álcali granitos, nefelina sienitos e granitos calcioalcalinos) (Windley 1995), interpretados como evidências para o reconhecimento da tafrogênese do Neoproterozoico.

Arcos magmáticos das regiôes de Arenópolis e Mara Rosa (850 Ma e $\mathrm{T}_{\mathrm{DM}} 1.000$ a $900 \mathrm{Ma}$ ) assinalariam um domínio oceânico entre a borda oeste do Cráton São Francisco e o lado oriental do Cráton Amazônico, propagando-se para NE (Pimentel \& Fuck 1992, Pimentel, Fuck \& Alvarenga 1996 e Pimentel et al. 2000). As informaçóes geocronológicas $(837 \pm 42 \mathrm{Ma})$ referentes a um dos gnaisses tonalíticos encontrados na porção leste da área estudada, indicam a cristalização de protólito análogo àqueles registrados para o Arco Magmático de Goiás $(856 \pm 13 \mathrm{Ma}$ ). A idade modelo do mesmo gnaisse tonalítico $(1,83 \mathrm{Ga})$, mais elevado que aquelas obtidas no Arco Magmático de Goiás, deixa em suspenso a hipótese de que terrenos relacionados a ambientes de arco, ocorram nessa regiáo. Por outro lado, este valor poderia estar indicando uma fonte já reciclada na crosta, o que não descartaria a possibilidade de resquícios de um arco magmático, tal qual aquele descrito em Goiás.

Iniciando um quadro de inversão tectônica, os sedimentos depositados nas bacias anteriormente descritas, foram envolvidos em processos metamórficos e deformacionais no Neoproterozoico e, passaram a estruturar os cinturóes metamórficos do CA. Estruturalmente foram geradas foliaçóes, xistosidade e bandamento, com mergulhos fracos a médios, estatisticamente para leste, na parte oriental e para quadrantes opostos nas partes central e ocidental, configurando grandes ondulaçóes, nappismo e imbricaçóes tectônicas (Abreu 1990). A macroestruturação do CA é concordante com a disposiçáo geral das rochas do embasamento, da porção ocidental, em razão da reativação de antigas zonas de deformação, provavelmente relacionadas à estruturação do Cinturão Granulítico do Médio Tocantins (Abreu 1990).

Finalmente, houve empilhamento e espessamento litosféricos, colocando lado a lado, níveis crustais diferentes e gerando fusões (Granitos Matança e Santa Luzia). Esse empilhamento no CA e na porção oeste da Província Tocantins está fartamente documentado em Abreu (1979, 1990), Costa (1985), Costa et al. (1983, 1984, 1988), Gorayeb (1996), Gorayeb et al. (2000), Moura \& Souza (1996).

Fusôes localizadas, associadas ao aumento do gradiente térmico, na porção leste da área do mapa, próximas ao contato com o Granito Matança, tiveram forte influência sobre os ortognaisses localizados ao longo desta faixa. As idades $(-550 \mathrm{Ma})$, registradas em alguns destes corpos, refletem sobrecrescimento de cristais e/ou zircóes neoformados durante a colocação do Granito Matança. Não se descarta a possibilidade de um metamorfismo de contato nesta zona.

\section{CONCLUSÕES}

O embasamento do Cinturão Araguaia é composto por um segmento norte (setentrional) e outro sul (meridional). Sua porção setentrional é representada por ortognaisses do Complexo Colmeia (2,85 Ga) e Gnaisse Cantão (1,85 Ga), 
que, conjuntamente, têm sido considerados como uma extensão do Cráton Amazônico para leste.

No segmento meridional o único vestígio do embasamento arqueano é o Grupo Rio do Coco (2,6 Ga), porém é representado majoritariamente, pelo CRM, um domínio geotectônico paleoproterozoico e pelo Granito Serrote. Em razão disso, este segmento crustal deve representar um terreno mais novo, justaposto às rochas arqueanas do Cráton Amazônico durante o Paleoproterozoico.

A história evolutiva na porçáo meridional, à luz de modelagens estruturais geométricas e cinemáticas desde Abreu (1990) e geocronológicas, mostra a ocorrência de múltiplos eventos geológicos.

Dois segmentos crustais pretéritos são apontados. Um a oeste, mais jovem, iniciou sua evolução a partir de 2,6 Ga. É marcado pela presença do greenstone belt do Grupo Rio do Coco e ainda pelo registro das idades modelo de 2,432,50 Ga, no Granito Serrote. O segundo, posicionado a leste, comporta rochas com protólitos $\left(\mathrm{T}_{\mathrm{DM}} 2,78-\right.$ 3,25 Ga) mais antigos registrados até agora na regiáo.

Um quadro de resto comum em várias regióes do mundo (Windley 1995) revela no início do Paleoproterozoico, um cenário antevisto para a área em estudo onde pontuaram platôs oceânicos, com reciclagem de crosta oceânica, arcos magmáticos e núcleos siálicos, de dimensôes e idades diversas, separados por uma crosta oceânica, de extensão desconhecida. A interação tectônica dessas entidades com os segmentos continentais, levou à edificação de um conjunto de rochas ortoderivadas que atualmente representam o CRM.

Os protólitos do CRM foram gerados a partir de duas fontes, uma mantélica $(2,21-2,25 \mathrm{Ga})$ e outra crustal $(2,35 \mathrm{Ga})$. Essa interação aconteceu durante encurtamento crustal, com colisôes, cavalgamentos e imbricaçóes tectônicas, associados ao fechamento de domínios oceânicos e a um evento metamórfico regional que atingiu condiçôes de alto grau há 2,1 Ga.

O Granito Serrote (1,86 Ga) e corpos restritos de natureza tonalítica e granítica $(1,85-1,82 \mathrm{Ga})$, resultantes da fusão parcial de compartimentos crustais manifestam esta condição.

Ao final do Paleoproterozoico, o cenário é o de um segmento crustal continental, com conjuntos litológicos desmembrados e imbricados, transportados de leste para oeste, no sentido do Cráton Amazônico, com orientaçôes submeridianas das foliações metamórficas e mergulhos preferenciais para leste.

No final do Mesoproterozoico foi iniciado processo de fragmentação, com magmatismo alcalino (Suíte Monte Santo e plutônicas máficas (peridotitos, Kotschoubey, Hieronymus \& Albuquerque 2005) descritas ao longo do
CA e formação de diversas bacias que acolheram rochas que originaram as supracrustais, dentre outras as do CA, que durante o seu processo evolutivo, alcançou o estágio de oceano restrito, com o desenvolvimento de um complexo ofiolítico.

As rochas alcalinas das Suítes Monte Santo (1,05 Ga) e Serra daEstrela $(1,01 \mathrm{Ga})$ são correlacionáveis e seus protólitos foram gerados durante o Mesoproterozoico $\left(\mathrm{T}_{\mathrm{DM}} 1,49-\right.$ 1,70 Ga). A Suíte Monte Santo pela sua natureza, idade e vinculação com a formação de bacias tafrogênicas é considerada reflexo da fragmentação do Supercontinente Rodínia, na região central do Brasil (Brito Neves et al. 1999) e aponta o "emplacement" na fase precoce da fissão do supercontinente, durante o Toniano.

O processo de fissão de Rodínia, permitiu a formaçáo de domínio oceânico que por reciclagem gerou o Arco Magmático de Goiás (?) (Pimentel et al. 2000, Pimentel, Jost \& Fuck 2004) ainda não descrito de forma clara na área trabalhada, mas prenunciado pelo aparecimento de um gnaisse tonalítico com idade de $840 \mathrm{Ma}$ e $\mathrm{T}_{\mathrm{DM}}$ $1,83 \mathrm{Ga}$.

Em novo processo de inversão das condições geodinâmicas no Neoproterozoico, a região experimentou espessamento crustal e fusóes, espacial e volumetricamente distintas, gerando os Granitos Matança e Santa Luzia.

Dessa movimentação tectônica resultou a edificação do CA, com feiçóes tectônicas meso e macroscópicas, realçadas por estruturas tectógenas. Ocorreu novamente, o transporte de massas tectônicas, no sentido do Cráton Amazônico, mimetizando o arranjo estrutural pretérito, resultando na atual arquitetura em que se encontram os conjuntos litoestruturais, na forma de lascas imbricadas e nappes.

Este modelo é comparável em parte àquele descrito para a região do Gurupi, na borda sul do Cráton São Luis que por sua vez encontra analogia com o quadro descrito na África Ocidental, borda leste do Cráton Oeste Africano.

\section{AGRADECIMENTOS}

Esse trabalho foi apoiado parcialmente pelo Conselho Nacional de Aperfeiçoamento de Pessoal de Nível Superior (CAPES) e Universidade Federal do Pará (UFPA) por meio do Programa de Pós-graduação em Geologia e Geoquímica, do Instituto de Geociências. Agradecimentos são extensivos ao Professor Dr. Paulo Sérgio de Souza Gorayeb pela sua participação nos trabalhos de campo e valiosas discussóes ao longo dessa pesquisa. 


\section{REFERENCES}

Abreu, F.A.M. 1979. Estratigrafia e evolução estrutural do segmento setentrional da faixa de dobramentos Paraguai-Araguaia. Dissertação de Mestrado. Universidade Federal do Pará, Belém, 90 p.

Abreu F.A.M. 1990. Evolução Geotectônica do Pré-Cambriano da região meio-norte do Brasil e sua correlação com a África Ocidental. Tese de Doutorado. Instituto de Geociências, Universidade Federal do Pará, Belém, 440 p.

Almeida F.F.M., Hasui Y., Neves B.B.B. 1976. The upper Precambrian of South America. Boletim IG-USP. Série Científica, 7:45-80

Almeida F.F.M., Hasui Y., Neves, B.B.B., Fuck R.A. 1977. Províncias Estruturais Brasileiras. In: SBG, Simp. Geol. Nordeste, 8, Atas, p. 363-391.

Almeida M.E., Macambira M.J.B., Valente S.C. 2008. New geological and singlezircon $\mathrm{Pb}$ evaporation data from the Central Guyana Domain, southeastern Roraima, Brazil: tectonic implications for the central region of the Guyana Shield. Journal of South American Earth Sciences, 26:318-328.

Alvarenga C.J.S., Moura C.A.V., Gorayeb P.S.S., Abreu F.A.M. 2000 Paraguay and Araguaia Belts. In: Cordani et al. Tectonic Evolution of South America. Rio de Janeiro, SBG. p. 183-194.

Arcanjo S.H.S. 2002. Evolução Geológica das seqüências do Embasamento na porção sul do Cinturão Araguaia-Região de Paraíso do Tocantins. Tese de Doutorado. Instituto de Geociências, Universidade Federal do Pará, Belém, 181 p.

Arcanjo S.H.S. \& Moura C.A.V. 2000. Geocronologia das rochas do embasamento do setor meridional do Cinturão Araguaia. Região de Paraíso do Tocantins (TO). Revista Brasileira de Geociências, 30(4):665-670.

Arcanjo S.H.S., Abreu F.A.M., Moura C.A.V. 2001. Magmatismo Alcalino Mesoproterozóico na Província Tocantins - Uma Evidência de Quebramento do Supercontinente Rodínia? In: SBG, Simp. Geol. Amazônia, 7, CD ROM.

Arcanjo S.H.S., Moura C.A.V., Abreu F.A.M., Gorayeb P.S.S. 2000. Rio do Coco Group: a 2.6 exotic terrain in the Paleoproterozoic Tocantins Shear Belt, Central Brazil. In: Intern. Geol. Congr., 31, CD ROM.

Arthaud M.H., Caby R., Fuck R.A., Dantas E.L., Parente C.V. 2008. Geology of the northern Borborema Province, NE Brazil and its correlation with Nigeria, NW Africa. Geological Society, London, Special Publications, 294:49-67.

Barreira C.F. 1980. Geologia, prospecção geoquímica e geofísica da área de Rio do Coco, Paraíso do Norte-GO. Dissertação de Mestrado. Universidade de Brasília, Brasília, 143 p.

Barreira C.F. \& Dardenne M.A. 1981. Seqüência vulcano-sedimentar do Rio do Coco. In: SBG, Simp. Geol. Centro-Oeste, 1, Atas, p. 241-264.

Basei M.A.S., Brito Neves B.B., Siga Jr. O., Babinski M., Pimentel M.M., Tassinari C.C.G., Hollanda M.H.B., Nutman A., Cordani U.G. 2010 Contribution of SHRIMP U-Pb zircon geochronology to unravelling the evolution of Brazilian Neoproterozoic fold belts. Precambrian Research, 183:112-144.

Bertotti A.L. 2005. Metodologia Samário/Neodímio: Uma abordagem analítica simplificada e alguns exemplos aplicativos. Dissertação de mestrado. Universidade Federal do Rio Grande do Sul, Porto Alegre, $105 \mathrm{p}$.

Brito Neves B.B., Pedrosa Soares A.C., Vidal P., Leonardos O.H. 1998. Neoproterozoic oceanic remnants in Eastern Brazil: further evidences and refutation of an exclusively ensialic evolution for the Araçuaí-West Congo orogen. Geology, 26(6):519-522.
Brito Neves B.B., Campos Neto M.C., Fuck R. 1999. From Rodinia to Western Gondwana: An Approach to the Brasiliano-Pan African Cicle and Orogenic Collage. Episodes, 22(3):115-166.

Brito Neves B.B., Santos E.J., Van Schmus W.R. 2000. Tectonic history of the Borborema Province, northeastern Brazil. In: Cordani U. Milani E.J., Thomaz Filho A., Campos D.A. (eds.). Tectonic Evolution of South America, Intern. Geol. Congr. 31, p. 151-182.

Costa J.B.S. 1985. Aspectos lito-estruturais e evolução crustal da região centro norte de Goiás. Tese de Doutorado. Instituto de Geociências, Universidade Federal do Pará, Belém, 209 p.

Costa J.B.S., Gorayeb P.S.S., Bermeguy R.L., Gama Jr. T., Kotschoubey B., Lemos R.L. 1983. Projeto Paraíso do Norte. Belém, UFPA, Conv. CVRD. $125 \mathrm{p}$

Costa J.B.S., Lemos, R.L., Martins J.P.M., Beltrão J.F., Góes A.M., Hasui Y. 1984. Geologia da região de Porto Nacional, GO. Revista Brasileira de Geociências, 14:3-11.

Costa, J.B.S.; Hasui, Y.; Gorayeb, P.S.S. 1988. Relações estruturais entre a Faixa Araguaia e o Maciço Goiano na região de Paraíso do Norte - Gurupi, GO. In: Congr. Bras. Geol., 35. Belém, 1988. Anais... Belém, SBG. v. 5, p. 2187-2196

Cruz V.L. \& Gorayeb P.S.S. 2008. Petrografia e significado do Complexo Ofiolítico Morro do Agostinho na Evolução do Cinturão Araguaia. In: SBG, Cong. Bras. Geol. 44, CD-ROM.

Delor C., Lahondéree D., Egal E., Lafon J.M., Cocherie A., Guerrot C., Rossi P., Trufert C., Teveniaut H., Phillips D., Avelar V.G. 2003. Transamazonian crustal growth and reworking as revealed by the 1:500.000 scale geological map of French Guiana (end edition). Géologie de la France, 2-3-4:5-57.

De Paolo D.J. 1981. Neodymium isotopes in the Colorado Front Range and crust-mantle evolution in the Proterozoic. Nature, 291:193-196.

De Paolo D.J. 1988. Neodymium isotope geochemistry: an introduction. Berlin, Springer-Verlag. 187 p.

Gaudette H.E., Abreu F.A.M., Lafon J.M., Gorayeb P.S.S. 1993. Evolução transamazônica do Cinturão de Cisalhamento Noroeste do Ceará, novas evidências geocronológicas. In: SBG, Simp. Geol. Nordeste, 13, Atas, p. 317-319.

Gorayeb P.S.S. 1996. Petrologia e evolução crustal das rochas de alto grau de Porto Nacional - TO. Tese de Doutorado. Instituto de Geociências, Universidade Federal do Pará, Belém, 258 p.

Gorayeb P.S.S., Moura C.A.V., Arcanjo S.H.S. 2000. Granitogenesis events in the Porto Nacional - Palmas - Paraiso do Tocantins region, Tocantins Province, Brazil. In: Internat. Geol. Congr. 31., CD ROM.

Gorayeb P.S.S., Gaudette H., Moura C.A.V, Abreu F.A.M. 1999. Geologia e Geocronologia da Suite Rosário, nordeste do Brasil. Revista Brasileira de Geociências, 29(4):571-578.

Gorayeb P.S.S., Pamplona L.J.P. \& Silva Neto J.J.A. 2011. Novas ocorrências de pillow basaltos no Cinturão Araguaia. In: Simp. Vulc. e ambientes associados, 5, CD-ROM.

Hadi H. El, Simancas J.F., Martínez-Poyatos D., Azor A., Tahiri A. Montero P. Fanning C.M. Bea F., González-Lodeiro F. 2010. Structural and geochronological constraints on the evolution of the Bou Azzer Neoproterozoic ophiolite (Anti-Atlas, Morocco). Precambrian Research, 182:1-14.

Hasui Y., Tassinari C.C.G., Siga Jr. O., Teixeira W., Almeida F.F.M. Kawashita K. 1980. Datações Rb-Sr e K-Ar do centro norte do Brasil e seu significado geológico-geotectônico. In: SBG, Cong. Bras. Geol., 31, Anais, 5, p. 2659-2667. 
Iwanuchi W. 1991. Geologia dos complexos alcalinos proterozóicos do centro do Estado do Tocantins. Tese de Doutorado. Instituto de Geociências, Universidade de São Paulo, São Paulo, 202 p.

Klein E.L. \& Moura C.A.V. 2001. Age constraints on granitoides and metavolcanic rocks of the São Luis Carton and Gurupi Belt, northern Brazil: implications for lithostratigraphy and geological evolution. Internacional Geology Review, 43:237-253.

Kotschoubey B., Hieronymus B., Albuquerque C.A.R. 2005. Disrupted peridotites ad basalts from the Neoproterozoic Araguaia belt northern Brazil): Remnants of a poorly evolved oceanic crust? Journal of South American Earth Sciences, 20:211-230.

Le Blanc M. 1981. The Late Proterozoic ophiolites of Bou Azzer (Morocco): evidence for Pan-African plate tectonics. In: Kröner A. (eds.), Precambrian Plate Tectonics. Elsevier, Amsterdam, p. 435-451.

Ledru P., Johan V., Milesi J.P., Tegyey M. 1994. Markers of the last stages of the paleoproterozoic collision: evidence for a 2,0 Ga. Continent involving circum-south atlantic provinces. Precambrian Research, 69:169-171.

Mabessone J.M. 2002. História Geológica da Província Borborema (NE Brasil). Revista de Geologia, 15:119-129.

Macambira M.J.B., Moura C.A.V., Lafon J.M., Scheller T. 1994. O método $\mathrm{Pb}-\mathrm{Pb}$ por Evaporação em Zircão: Avaliação dos Dados Obtidos no Laboratório de Geologia Isotópica da UFPA. In: SBG, Cong. Bras. Geol., 38, Anais, p. 404-406.

Moura C.A.V. 1992. Geochronology and geochemistry of the Basement orthogneisses of the Araguaia Belt, Brasil. Tese de Doutorado. University of New Hampshire, New Hampshire, 236 p.

Moura C.A.V. \& Gaudette h.E. 1993. Zircon Ages of the Basement Orthogneisses of the Araguaia Belt, North - Central Brazil. In: Cong. Bras. Geoq., 4., Bol. Res. Exp., p. 232-234.

Moura C.A.V. \& Gaudette H.E. 1994. Geochemistry of the basement orthogneisses of the Araguaia Belt, Tocantins-Brazil. In: SBG, Cong. Bras. Geol., 38, Anais, 2, p. 240-241.

Moura C.A.V. \& Gaudette H.E. 1999. Zircon ages of basement orthognaisses from the northern segment of the Araguaia Belt, Brazil. Basement Tectonics, 13:155-178.

Moura C.A.V. \& Souza S.H.P. 1996. Síntese dos dados Geocronológicos das rochas do Embasamento do Cinturão Araguaia e suas Implicações Estratigráficas. In: SBG, Cong. Bras. Geol., 39, Anais, 6, p. 31-34.

Neves S.P. 2003. Proterozoic history of the Borborema Province (NE Brazil): correlations with neighboring cratons and Pan-African belts, and implications for the evolution of western Gondwana. Tectonics, 22:10-31.

Paixão M.A.P., Nilson A.A., Dantas E.L. 2008. The Neoproterozoic Quatipuru ophiolite and the Araguaia fold belt, central-northern Brazil, compared with correlatives in NW Africa. Geological Society, London, Special Publications, 294:297-318.

Palheta E.S.M. 2001. Evolução Geológica da Região Nordeste do Estado do Pará com base em Estudos Estruturais e Isotópicos de Granitóides. Dissertação de Mestrado. Instituto de Geociências, Universidade Federal do Pará, Belém, 143 p.

Palheta E.S.M, Abreu F.A.M \& Moura C.A.V. 2009. Granitóides proterozóicos como marcadores da evolução geotectônica da região nordeste do Pará, Brasil. Revista Brasileira de Geociências, 39(4): 647-657.
Pimentel M.M. \& Fuck R.A. 1992. Neoproterozoic crustal accretion in central Brazil. Geology, 20(4):375-379.

Pimentel M.M., Fuck R.A., Alvarenga C.J.S. 1996. Post-Brasiliano (Pan-African) high-K granite magmatism in central Brazil: late Precambrian/early Paleozoic extension. Precambriam Research, 80:217-238.

Pimentel M.M., Fuck R.A., Gioia S.M.C.L. 2000. The Neoproterozoic Goias magamtci arc, central razil: a review and new Sm/Nd isotopic data. Revista Brasileira de Geociências, 30(1):35-39.

Pimentel M.M., Fuck R.A., Jost H., Ferreira Filho C.F., Araújo S.M. 2000. The Basement of the Brasília fold Belt and the Goiás Magmátic Arc. In: Cordani et al. Tectonic Evolution of South America. Rio de Janeiro, SBG, p. 195-229.

Pimentel M.M., Jost, H.Fuck R.A. 2004. O embasamento da Faixa Brasilia e o Arco Magmático de Goias. In: Mantesso Neto V., Bartorelli A., Carneiro C.D.R., Brito Neves B.B. (orgs). Geologia do Continente Sulamericano: Evolução da obra de Fernando Flávio Marques de Almeida. São Paulo, Beca. p. 355-368.

Sato K. \& Tassinari C.C.G. 1997. Principais eventos de acresção continental no Cráton Amazônico baseados em idades modelo Sm-Nd, calculada em evoluções de estágio único e estágio duplo. In: Costa M.L.S. \& Angélica R.S. (coord.) Contribuição a Geologia da Amazônia. SBG-NO, p. 91-142.

Sato K. \& Siga Jr. O. 2000. Evidence of the superproduction of the continental crust during Paleoproterozoic in South American Platform. Implications regarding the interpretative value of the Sm/ Nd model ages. Revista Brasileira de Geociências, 30(1):126-129.

Sousa D.J.L. \& Moura C.A.V. 1996. Estudo Geocronológico do Granito Serrote, Paraíso do Tocantins. In: Cong. Bras. Geoq., 5 e Cong. Geoq. Países Líng. Port., 3, CD-ROM.

Souza S.H.P. 1996. Geologia e Geocronologia da Região a sul de Paraíso do Tocantins. Dissertação de Mestrado. Instituto de Geociências, Universidade Federal do Pará, Belém, 127 p.

Souza S.H.P. \& Moura C.A.V. 1995. Idades Pb-Pb em Zircões das Rochas do Embasamento do Cinturão Araguaia na Região de Paraíso do Tocantins (TO). In: Simp. Nac. Est. Tect. 5, Bol. Res. Exp., p. 95-97.

Souza S.H.P. \& Moura C.A.V. 1996. Considerações Estratigráficas, com base em Datações Geocronológicas, para as Rochas Graníticas de Paraíso do Tocantins (To). In: SBG, Simp. Geol. Amazônia, 5, Anais.

Van Schmus W.R., Oliveira E.P., Silva Filho A.F., Toteu S.F., Penaye J., Guimarães I.P. 2008. Proterozoic links between the Borborema Province, NE Brazil, and the Central African Fold Belt. In: Pankhurst R.J., Trouw R.A.J., Brito Neves B.B., Wit M.J. (eds.). West Gondwana: Pre-Cenozoic Correlations Across the South Atlantic Region. Geological Society, London, Special Publications, 294:69-99.

Villas R.N.N. 1982. Geocronologia de intrusões ígneas na bacia do rio Guamá, nordeste do Estado do Pará. In: SBG, Simp. Geol. Amazônia, 1, Atas, 1, p. 233-247.

Windley B.F.1995. The Evolving Continents. 2.ed. New York, John Willey and Sons. 526 p.

$\overline{\text { Arquivo digital disponível on-line no site www.sbgeo.org.br }}$ 